\title{
Gobiernos, modernidad y producción escrita en Colombia (1880-1930): la escritura como terreno común de los antagonismos
}

Carlos Arturo López J.

Artículo recibido: 17 de enero de 2014
Artículo aprobado: 3 de marzo de 2014

Doi: dx.doi.org/10.12804/desafios26.02.2014.02

Para citar este artículo: López, C. A. (2014). Gobiernos, modernidad y producción escrita en Colombia (1880-1930): la escritura como terreno común de los antagonismos. Desafios, 26 (2), 43-71. doi: dx.doi.org/10.12804/desafios26.02.2014.02

\section{Resumen}

Las investigaciones en historia de Colombia, además de algunas en sociología y filosofia, han usado la producción escrita de este país como fuente para comprender asuntos relativos a los partidos politicos, las administraciones públicas o la modernización política, cultural y económica. Sin embargo, al concentrar su lectura en los gobiernos y la modernidad, han recortado el contenido y el significado de dichos documentos en lugar de establecer — antes de hacer uso de ellos — la naturaleza del ejercicio que los hace posibles; de esta manera se generan problemas de interpretación de los escritos colombianos y del tema mismo que se pretende abordar a partir de ellos. El grueso de este articulo presenta con mayor detalle este diagnóstico sobre la interpretación de la producción escrita en Colombia y termina señalando un terreno que permita pensar las lineas generales de las condiciones históricas que hicieron posible la actividad intelectual colombiana.

\footnotetext{
* Investigador del Instituto de Estudios Sociales y Culturales (PENSAR), de la Pontificia
} Universidad Javeriana, Bogotá, Colombia. 
Palabras clave: Colombia, modernidad, producción escrita, actividad intelectual, escritores colombianos, gobiernos conservadores, "minimo textual".

\title{
Governments, Modernity and Written Production in Colombia (1880-1930): Writing as a Common Space of Antagonisms
}

\begin{abstract}
Research papers on Colombian history, as well as on sociology and philosophy, have usually resorted to the country's written production as a source of information to better understand matters related to political parties, public administrations, or political, cultural, and economic modernization. However, by focusing those readings on governments and modernity, they have left out and therefore reduced the relevant documents' content and significance instead of establishing — before putting them to whatever use - the nature of the practice that enabled those writings, thus bringing about problems of interpretation vis-à-vis both the relevant texts and their subject matter. The main purpose of this article is to present in more detail the abovementioned diagnosis regarding the interpretation of the country's written production and to point out a space where reflection on the general historical conditions that allowed for such intellectual activity becomes possible.
\end{abstract}

Keywords: Colombia, modernity, written production, intellectual activity, Colombian writers, Conservative governments.

\section{Governos, modernidade e produção escrita na Colômbia (1880-1930): a escritura como terreno comum dos antagonismos}

\begin{abstract}
Resumo
As pesquisas em história da Colômbia, além de algumas em sociologia e filosofia, têm usado a produção escrita deste país como fonte para compreender assuntos relativos aos partidos políticos, as administrações públicas ou a modernização política, cultural e econômica. No entanto, ao concentrar sua leitura nos governos e a modernidade, têm recortado o conteúdo e significado de ditos documentos em vez de estabelecer — antes de fazer uso deles - a natureza do exercício que os fazpossiveis; desta forma
\end{abstract}


geram-se problemas de interpretação dos escritos colombianos e do tema mesmo que pretende-se abordar a partir deles. O grosso deste artigo apresenta com maior detalhe este diagn Lostico sobre a interpretação da produção escrita na Colômbia e termina assinalando um terreno que permita pensar as linhas gerais das condicões históricas que fizeram possivel a atividade intelectual colombiana.

Palavras chave: Colômbia, Modernidade, produção escrita, atividade intelectual, escritores colombianos, governos conservadores, "mínimo textual".

¿Cuál es la causa de que un actor se defina a base de pruebas? Simplemente, que no existe ningún modo de definir a un actor como no sea a través de la observación de sus actos.

Bruno Latour

\section{La escritura subordinada a la administración pública}

La actividad intelectual colombiana entre 1880 y 1930 tuvo aspectos en común con la que se realiza en la actualidad. En aquel entonces - como hoy - quienes la llevaban a cabo se reconocían por sus producciones escritas en publicaciones seriadas y volúmenes independientes; por su intercambio con pares en el país y fuera de este, mediante la correspondencia y la lectura de lo que publicaban; por su participación activa en conversaciones informales y eventos públicos; en muchos casos, por su acceso a la educación superior, la cual desempeñaba un papel importante - aunque no tanto como en la actualidad - para ser reconocido como un "escritor". No pocos de quienes alcanzaron dicho reconocimiento hicieron esfuerzos por ir al exterior y aprender otras lenguas; ambas cosas les ayudaban en la consolidación de una imagen pública y les aportaban información de primera mano sobre la actividad intelectual internacional — la posesión de esta información era, sin duda, un factor que también elevaba el prestigio entre los pares-.

En aquel entonces un escritor debía sentar posición sobre cuestiones de la vida nacional a través de medios como la prensa. También, dar apoyo a sus copartidarios, participar en los diferentes comicios para ocupar cargos de elección popular o atender el llamado de los admi- 
nistradores públicos de turno para hacer parte del gobierno. Ellos, incluso, hacían proselitismo en las cátedras que tenían a cargo, pues era común que estas dependieran de compromisos con quienes hacían parte del gobierno. ${ }^{1}$

Esa presencia diversa en la vida pública fue determinante para ser reconocido como escritor en buena parte de la historia del actual territorio colombiano. De hecho, ser escritor fue muchas veces importante si se quería participar de la vida pública, por ello Gilberto Loaiza Cano afirma:

Una ojeada a nuestra historia de la literatura revela que esa historia tiene vínculos a menudo muy directos con lo político: muchas generaciones de creadores literarios están asociadas con procesos políticos, muchos escritores han tenido un recorrido político en alguna parte de sus trayectorias, y sus obras han sido y serán, de una u otra manera, fuente para reconstruir el paisaje de la vida pública en algún segmento histórico (Pérez Benavides y Hering Torres, 2012, p. 349).

Según Gonzalo Sánchez, en Colombia se puede hablar de la existencia de este tipo de escritores a partir del "proceso de diferenciación de la intelectualidad nativa —el intelectual patriota — que había iniciado desde los tiempos de las reformas borbónicas y de la Revolución Comunera [1781]... [y] se fortaleció con el movimiento de la Expedición Botánica [el cual duró alrededor de treinta años a partir de 1783]" (Sánchez Gómez, Pécaut y Uricoechea, 2003, p. 58). Durante la vida republicana, la consolidación del grupo social dedicado a las actividades intelectuales continuó con las reformas universitarias de Francisco de Paula Santander (en los años veinte del siglo XIX), la introducción y los debates en torno al benthamismo (proceso intermitente que

\footnotetext{
1 Respecto a los compromisos extracadémicos de la educación a finales del siglo XIX en Colombia, afirma James Henderson: "Los profesores colombianos del siglo XIX pudieron haber transmitido valores victorianos en el aula, pero, a través de sus acciones públicas, revelaron que gran parte de lo que enseñaban estaba cargado de significado político. Esto era tan cierto en la década del noventa como lo había sido durante el anterior medio siglo" (Henderson, 2006, p. 43).
} 
inicia en 1824 y termina alrededor de 1870), la Comisión Corográfica (a cargo de Agustín Codazzi entre 1850 y 1859), y la fundación de la Universidad Nacional (1868).

Durante los gobiernos que van de 1880 a 1930, este desarrollo se habría visto afectado por la restitución a la Iglesia católica de muchos de los privilegios perdidos durante las reformas de mitad de siglo. ${ }^{2}$ Concretamente, en 1887 el gobierno colombiano puso en marcha un pacto con dicha iglesia conocido como el Concordato. Allí, además de devolvérsele a ella la orientación de la educación pública se le concedió la autoridad para limitar la circulación de escritos y doctrinas a partir de lo indicado por el Vaticano en documentos como el Sillabus (1864) o las encíclicas Quanta cura (1864) y Aeterni Patris (1879). Por todo ello, por los vínculos con el conservadurismo colombiano de la mayoría de los presidentes del periodo y porque se subrayan las políticas de mano dura de los gobiernos de esos años, una larga tradición define este periodo como conservador y lo divide en dos etapas. Por comodidad y para precisar una no muy clara convención historiográfica, en adelante esas etapas se identificarán así: la primera etapa, que termina en 1899, es la Regeneración; la segunda, que oficialmente comienza en 1903, es la hegemonía conservadora. Al periodo en su conjunto se le dirá república conservadora:

La Regeneración, y a la larga la República Conservadora, significaban por consiguiente una incuestionable interrupción en el proceso de acercamiento al mundo experimental que se había iniciado desde los tiempos de Mutis y de Caldas [en las postrimerías del periodo colonial y aún después de 1810], y reafirmaban una característica disociación, la de la modernización económica y política, por un lado y tradicionalismo cultural, por el otro. Saberes exegéticos (gramática y derecho), pasado hispánico y estructuras

\footnotetext{
2 Comúnmente se llama reformas de mitad de siglo al periodo de la historia de Colombia en el que se hacen modificaciones sustanciales a la estructura social y política del país con el fin de ajustarlo a las políticas internacionales de corte liberal y superar la estructura colonial de la sociedad que habría sobrevivido a las guerras de Independencia. Como consecuencia de estas reformas llegará el federalismo y se restringirán severamente los privilegios que la Iglesia católica tenía ganados desde tiempos de la Colonia.
} 
clericales, conformaban el sustrato básico de las jerarquías y el poder en la sociedad finisecular (Sánchez Gómez, Pécaut y Uricoechea, 2003, p. 63).

Durante la República Conservadora, aquellos quienes se dedicaron a la actividad intelectual fundamentaron y legitimaron los diversos gobiernos, hicieron defensas de las medidas tomadas por ellos o contestaron los múltiples ataques que sufrieron sus copartidarios, el partido al que estaban afiliados o la administración de turno. Por ello se afirma que en este periodo de administraciones conservadoras la producción escrita habría estado, exclusivamente, al servicio de la acción de los gobernantes, en particular cuando, como era común, los dos roles eran desempeñados por la misma persona.

La situación volvería a cambiar en 1930 con el comienzo de la República Liberal (1930-1946), una serie de gobiernos liberales considerada por lo regular la causa de la aceleración de los procesos de crecimiento económico, fortalecimiento social y maduración cultural de Colombia (entre esos procesos se cuenta la profesionalización de la actividad intelectual). ${ }^{3}$ Durante este periodo los saberes, en general, y las ciencias sociales, en particular, habrían sido empleados en el ejercicio de gobierno con el fin de identificar y resolver problemas concretos de la vida nacional. ${ }^{4}$ Así, su función se habría enfocado no tanto en

\footnotetext{
3 Respecto a los intelectuales de finales de los años veinte, afirma Rubén Jaramillo Vélez que se trató de "una generación que emerge de un proceso de modernización que se acelera considerablemente a finales de la década del 20 y en el 30 puede disfrutar del ambiente más secular que caracteriza a la 'República Liberal' en su intento por modernizar el país y adecuarlo al desarrollo del capitalismo [...] No se puede negar que la política educativa de los regímenes liberales favoreció la gestación de un clima que haría posible la regularización y profesionalización de la actividad intelectual en el país" (Jaramillo Vélez, 1998, p. 104).

4 Al respecto afirma Renán Silva: "La idea de conocimiento científico de la realidad —una idea de cierta novedad en los años 30 del siglo xx, cualquiera que fuera su orientación particular-y de procesos de investigación social (sobre todo por la vía de la 'encuesta') aplicados al conocimiento de esa sociedad — una idea también moderna— se ligaba de manera orgánica con el proyecto de creación de instituciones de alta cultura cuya meta debería ser la formación de una nueva intelectualidad. Nueva, en una doble acepción. Primero por la relación de distancia que establecería con respecto a los partidos políticos tradicionales - incluido el propio partido inspirador de los proyectos, con su reconocida y secular tendencia sectaria-. Segundo por el dominio de un instrumental de método y de teoría que fuera no solo garantía de una re-
} 
cuestiones ideológicas — como ocurriera en el periodo anterior-, sino en asuntos administrativos.

Según lo anterior, durante República Liberal se operó una transformación en la vida intelectual a través de la utilización novedosa de los diversos saberes: ya no se usarían más tiempo, o al menos ya no solamente, para dar prestigio a las élites, para mantener unos privilegios que habrían permanecido desde tiempos coloniales, para defender la jerarquía eclesiástica y su pretensión de mantener su poder temporal sobre los ciudadanos; en síntesis, el saber ya no se reduciría a un simple utensilio para la perpetuación de un grupo en el poder, como — si se sigue la común afirmación de la literatura sobre el tema- habría ocurrido con una regularidad aplastante y sin ninguna otra finalidad durante la Regeneración y la Hegemonía Conservadora.

La historiografía sobre Colombia que directa o indirectamente se ha ocupado de comprender la historia de la actividad intelectual en este país tiende a concentrase en el tipo de servicio que quienes la ejercían les prestaron a la administración pública, a las élites económicas y otros grupos privilegiados de los cuales ellos eran parte. ${ }^{5}$ Tales intentos muestran con claridad la transformación del oficio de escritor (Sánchez, 1998, pp. 115-138; Urrego Ardila, 2002) y, además, explican por qué 1930 es el año con el que convencionalmente se inicia la historia de la actividad profesional y el punto en el que comenzarían a producirse los primeros documentos de carácter científico con algún

lativa objetividad en el conocimiento, sino también de distancia frente al mundo tradicional de la política y de los políticos, tal como este se vivía de manera tradicional desde la propia fundación de la República” (2006, p. 39).

5 Se habla de privilegiados porque los niveles de alfabetización siguen siendo bastante bajos hasta la segunda mitad del siglo XIX, incluso a comienzos del siglo Xx la situación permanecía con pocos cambios: "En 1900 la tasa de analfabetismo como porcentaje de la población adulta en Colombia (66\%) se encontraba entre las más altas de América Latina. De hecho, Colombia tenía un 20\% más de personas analfabetas que Argentina y $10 \%$ más que Chile. En cuanto al porcentaje de alumnos matriculados en primaria, dentro de la población total Colombia tenía el 3,5\% en 1900, cifra bastante inferior, por ejemplo, a la exhibida por Argentina (8,4\%), Costa Rica (6,1\%) y Chile (5,3\%)" (Uribe Escobar, 2006). 
reconocimiento por los académicos contemporáneos (Sierra Mejía, 1985; Jaramillo Vélez, 1998; Gil Olivera y Ortiz Rivas, 2008). Entre 1880 y 1930 habría muy poco o nada que decir más allá de este servicio, y aunque no obstante muchos documentos pueden probar esta afirmación, ella entraña algunos problemas.

Por un lado, se ocultan aspectos importantes de la obra que se quiere comprender cuando, como primer requisito del análisis, se parte de la ubicación de su autor dentro de una administración y un partido político. Primero, porque este procedimiento exige pensar las relaciones de los escritores y los gobernantes como un dato fundamental en la lectura de los textos producidos por los primeros y, segundo, porque reduce la importancia de los textos a dicha relación y a su utilidad. Estas dos condiciones resultan problemáticas, porque en el periodo de interés, de entre las múltiples acciones características de quienes se dedicaban a actividades intelectuales (tertulias, correspondencia, orientación a gobernantes, ejercicio en cargos públicos, lectura y educación formal), solo la escritura les daba la visibilidad y el reconocimiento público entre los lectores, en general, y entre sus pares, en particular. Es decir, ella desempeñaba un papel tan importante que no parece legítimo reducirla a sus relaciones con los gobiernos de turno. Además, concentrarse en los servicios que los escritores les prestaban a estos últimos, aun si el objetivo es dar cuenta de las relaciones con los administradores públicos de turno, es insuficiente, pues si en cuanto parte de los grupos en el gobierno se está en una posición ventajosa, ¿para qué escribir tanto como lo hacían? ¿Para qué dar razones si con la fuerza que otorgaban la retórica y las armas podían perpetuar su propia situación de privilegio?

$\mathrm{Al}$ respecto de esta fuerza, afirma el historiador norteamericano James Henderson:

Durante las primeras décadas del siglo [xx] y más allá de ellas, la mayoría del pueblo colombiano eran espectadores políticos que aclamaban a los dirigentes nacionales famosos, estrellas de los partidos tradicionales a quienes estaban apasionadamente apegados, a menudo a nivel del interés personal. La política significaba 
empleos, control de las políticas públicas y, en algunos casos, seguridad personal o falta de ella. Y, además era un espectáculo maravilloso. La política nacional estaba llena de drama, y ofrecía al espectador una serie interminable de anécdotas cargadas de emoción, que se desarrollaban con la regularidad de un moderno melodrama. Y, desde luego, era gratuita —al menos a corto plazo-(Henderson, 2006, pp. 139-140). ${ }^{6}$

Con tanta atención de los ciudadanos por esta "puesta en escena", con tantos intereses en juego y, muchas veces, con las vidas de personas puestas en entredicho, ¿qué papel podría desempeñar la preparación y publicación de largos documentos, cuidadosamente redactados y argumentados? Resultaría difícil cuestionar la visibilidad y el prestigio social que otorgaba la escritura pública, pero no por ello se pueden limitar los textos a esta visibilidad y este prestigio o, como se dijo antes, a la subordinación de los escritores a los gobernantes.

La historia de la actividad intelectual al servicio de la administración pública, en lugar de revisar los contenidos concretos de lo que se escribió y entender su propia dinámica, sus formas de argumentación, además de los temas y problemas de que se ocupan las miles de páginas que se escribieron, recurre a los textos con el único fin de determinar su funcionalidad estratégica, su lugar en el gobierno y las contiendas eminentemente ideológicas. Así, los largos y detallados escritos de conservadores como Miguel Antonio Caro (1943-1909), Marco Fidel Suárez (1855-1927), Laureano Gómez (1889-1965) o Silvio Villegas (1902-1972) se resumen de un plumazo a través de las más panfletarias y dogmáticas sentencias de sus escritos acerca de la importancia del catolicismo, la necesidad de recuperar los vínculos con España o la atención que debe tenerse en el uso de la lengua materna; además, se toman tales sentencias y se traza una relación causal directa entre ellas y las acciones de los dirigentes colombianos. De este modo, se pretende tener una explicación de los abusos de los gobernantes y, en general, de las élites. Pero, si bien es cierto que durante los gobiernos

\footnotetext{
6 Esta imagen de la política como entretención también coincide con la presentación que hace Ricardo Arias (2007) en su libro "Los Leopardos": una bistoria intelectual de los años 1920.
} 
entre 1880 y 1930 hubo excesos de violencia y dogmatismo, en parte justificados mediante la producción escrita, con afirmarlo sin más se siguen pasando por alto los debates concretos entre escritores y gobernantes, entre escritores y sus pares, entre escritores y el público lector. Se siguen desdeñando las respuestas a situaciones específicas que dieron forma a dichos textos y, lo que resulta más problemático, se siguen usando esos escritos como fuentes, como explicaciones de hechos históricos, aun cuando la parcialidad con que se leen salta a la vista.

Por otro lado, una historia de la actividad intelectual concentrada en la relación que los pensadores de la Regeneración y la República Conservadora tuvieron con los administradores públicos de turno mutila el proceso de la vida intelectual colombiana a través del señalamiento de cierto "oscurantismo" suscitado por los gobiernos conservadores, como si el desarrollo de la producción escrita hubiera entrado en un coma del que solo saldría con el impulso vital dado por los liberales. Imagen distorsionada de un proceso, de la que con regularidad se concluye que se detuvo, que fue deficitario o que asumió una naturaleza anormal. Pero, ¿cómo se detiene un proceso histórico? ¿Desde qué criterios se afirma su anormalidad?

\section{La historiografía y la modernidad}

La historia de la actividad intelectual ligada a la administración de lo público dificulta comprender la producción escrita en Colombia, porque oculta el contenido efectivo de los textos, en virtud del provecho que podían hacer de ellos los gobernantes, y diagnostica una "hibernación" de la actividad intelectual durante los gobiernos de la Regeneración y la República Conservadora. Ese diagnóstico ha sido posible, pues por lo común se asume una especie de destino hacia el que Colombia necesariamente debería dirigirse; el proceso y el culmen de ese recorrido suelen nombrarse con expresiones relativas a la idea de "modernidad" (moderno, modernización, modernista o modernizador). Gracias a la necesidad con que se insufla el carácter procesual y teleológico de esta idea, se acusa a la República Conservadora de pro- 
ducir una endémica premodernidad ${ }^{7}$ o una errónea paramodernidad, ${ }^{8}$ una postergación (Jaramillo Vélez, 1998) o una imposibilidad para alcanzar (Rodríguez Valbuena, 2003) dicha modernidad, incluso, una simultaneidad de temporalidades que harían una anómala combinación de momentos previos, posteriores y concomitantes a esa modernidad de la que tanto se habla. ${ }^{?}$

\section{Una buena caracterización del uso extendido de ese término en la historia de Colombia se encuentra en un libro de Carlos Humberto}

7 Uno de los ejemplos más claros de esta concepción de la modernidad colombiana son los trabajos de Salomón Kalmanovitz. En la presentación de su breve artículo titulado "Modernidad y competencia" afirma: "La idea central que pretendo desarrollar en este ensayo es la de los rezagos de la mentalidad cristiano-feudal [...] que acompañan las relaciones sociales que se reproducen dentro de los negocios y el Estado en el país colombiano" (Viviescas y Giraldo Izasa, 1991, p. 311). En otro texto, a propósito de las instituciones colombianas, sostiene que el gran problema de la nación ha sido el que sus ciudadanos no asumen responsabilidad individual por sus actos o sus condiciones de vida; por ello, cada persona busca una instancia superior que responda por sus actos y su cuidado; en síntesis, Colombia ha carecido de ciudadanos que encaren las obligaciones de las subjetividades modernas (Kalmanovitz, 2001).

8 Una clara imagen de este tipo de comprensión de la modernidad la presenta José Luis Villaveces Cardoso en su ensayo "Modernidad y ciencia": "Mientras que en el mundo se debaten distintos caminos para entrar en la postmodernidad, en Colombia parece aún urgente alcanzar la modernidad. Estamos llenos de artefactos modernos de consumo, desde neveras y televisores hasta discos láser y metralletas; sin embargo, nuestra cultura es fundamentalmente premoderna o paramoderna: transcurre al lado de la modernidad e incluso se inspira en sus paradigmas pero no la incorpora al actuar cotidiano. Nuestros industriales no han desarrollado dinámicas de innovación y actúan fundamentalmente con mentalidad de rentistas, al igual que nuestros burócratas, que utilizan como hacienda al Estado; recurrimos continuamente a la violencia como única forma de dirimir nuestros conflictos y tenemos un pensamiento mágico para explicar y dominar la naturaleza” (Viviescas y Giraldo 1991, p. 326).

9 "[...] todo ello como base cultural atrasada y premoderna a partir de la cual, sin embargo, se ha cumplido el gran éxodo de la movilidad social y del posicionamiento plebeyo "hacia arriba", en oleadas de todo orden, en procura de los justísimos ideales de la libertad y la igualdad, ya modernos. A todo lo cual se suman, como si lo anterior fuera poco, sobredosis de elementos postmodernos que nos llega a través de los medios masivos de comunicación, desde las sociedades y civilizaciones postindustriales. De esta manera, en nuestras barriadas populares urbanas tenemos camadas enteras de jóvenes, incluso adultos cuyas cabezas dan cabida a la magia y a la hechicería, a las culpas cristianas y a su intolerancia piadosa, lo mismo que al mesianismo y el dogma estrecho e hirsuto, a utópicos sueños de igualdad y libertad, indiscutibles y legítimos, así como a sensaciones de vacío, ausencia de ideologías totalizadoras, fragmentación de la vida y tiranía de la imagen fugaz y el sonido musical como lenguaje único de fondo" (Viviescas y Giraldo, 1991, p. 391). 
Uribe Celis sobre los años veinte del siglo pasado: "los días en que se dio el paso decisivo hacia la modernización del país" (1985, p. 23). El libro en cuestión afirma que en esta década de "despegue" se aceleran los procesos de transformación económica y cultural que favorecerán a Colombia en su inserción al capitalismo:

Creemos que en los 20 el país avanza hacia la restauración de una moral capitalista contra el predominio de dogmas y normas de corte feudal cuyos obstáculos al avance del capital y a la construcción del hombre nuevo deben superarse. Lo anterior no puede entenderse más que en un sentido relativo, pues la terrible y gigantesca maquinaria ideológica que la religión había montado en Colombia era aún demasiado fuerte para ceder a los empujes de inclinaciones o fuerzas germinales (Uribe Celis, 1985, pp. 43 y 44).

En este tipo de historiografía lo que se nombra con la palabra modernidad y el paquete de palabras asociadas con ella se opone al catolicismo $\mathrm{y}$ a las fuerzas que se unieron a su proyecto, fuerzas que en general se identifican como conservadoras, hispanistas o tradicionalistas (dogmáticas y autoritarias en todos los casos).

En esta misma línea se mueven los historiadores de la filosofía. Rubén Jaramillo Vélez (1998), por ejemplo, en un libro titulado La modernidad postergada, afirma que Bogotá a finales del siglo XIX y comienzos del XX, desde este entonces y hasta la actualidad capital del país, habría estado sumida en prejuicios coloniales (no sobra decir: atados a España y el catolicismo) y no habría desarrollado las bases mínimas de una industrialización de tipo capitalista. Por ello, solo a partir de la década de los veinte, y debido al fuerte impulso de la economía cafetera, ${ }^{10}$ al surgimiento de nuevos productos hechos y comerciados por peque-

\footnotetext{
10 " [...] el café crea en Colombia las clases sociales, previa la conservación de los grupos que ya existían en la aldea - jornaleros y propietarios territoriales-. Suscita la formación de una economía capitalista, después de haber ampliado el mercado interno para la futura producción industrial. La burguesía y el proletariado son las nuevas clases sociales. Hay, también, los grandes exportadores de café. El aumento de las importaciones, a raíz de la mayor demanda, nos da el comerciante al por mayor, nacional o extranjero. El cuadro queda completo. El café es una revolución económica" (Nieto Arteta, 1958, p. 79).
} 
ños propietarios y a la consolidación de un sector industrial, pensadores de otros lugares de Colombia (Antioquia, occidente; el Viejo Caldas, en el centro; la costa Atlántica, al norte, y los Santanderes, al oriente $)^{11}$ se habrían puesto en la tarea de sentar las bases de la filosofía moderna. Sin embargo, solo tardíamente - -luego de la segunda guerra mundial— se consolidaría la actividad filosófica "normal" en el país.

Esta imagen de la "postergación de la modernidad" se asoció con la idea de normalización de la filosofía, acuñada por el filósofo argentino Francisco Romero ${ }^{12}$ y, al menos en Colombia, se ha usado para señalar el estado de "atraso nacional" respecto a un proceso mundial del que "debió" participar la filosofía colombiana a lo largo de los siglos XIX y xx. En esta misma línea se encuentra el libro La filosofía en Colombia: modernidady conflicto, de Manuel Guillermo Rodríguez Valbuena:

La filosofía de la Regeneración aporta muy poco al pensamiento filosófico pues representa una hibridación anómala de conceptos anacrónicos. Logró desarrollarse en el campo de las conveniencias políticas de la alianza de las clases que ejercía el poder a finales del siglo XIX, lo cual implica un forzamiento violento de las tendencias históricas del pensamiento, con consecuencias funestas para la cultura filosófica (2003, p. 191).

11 El proceso de establecimiento de la filosofía moderna en Colombia se reforzó en las regiones distantes de la capital porque, al menos en Antioquia y Caldas, se contaba, para la fecha, con más altas tasas de alfabetización que en Bogotá (Arias, 2007, p. 41).

12 " [...] ejercicio de la filosofía como función ordinaria de cultura, al lado de las otras ocupaciones de la inteligencia [...] Como cualquier oficio teórico, la filosofía permite y aún requiere el aporte de mentes no extraordinarias: basta el indispensable sentido para estos problemas, la seriedad, la información, la disciplina. La lectura corriente de escritos filosóficos por interesados cada día más numerosos, el mutuo conocimiento e intercambio entre quienes activamente se ocupan en filosofía, van originando lo que podríamos denominar el 'clima filosófico', una especie de opinión pública especializada que obra y obrará cada vez más, y según los casos, como estímulo y como represión, como impulso y como freno: esto es, como una vaga, indeterminada sanción continua que antes y después de los juicios expresos de la crítica, corrigiendo lo que hubiera en estos de partidismo y apreciación individual, promoverá calladamente ciertas cosas, impedirá o dificultará otras, distinguirá planos y establecerá jerarquías" (Romero, 1944, s. p.). 
Según el autor, los esfuerzos liberales por modernizar el país asociados con la integración mundial y las reformas tendientes a la secularización no fueron fructíferos en buena medida porque los regeneradores se impusieron con violencia. Como consecuencia de ello se retrasó el ingreso de Colombia a la modernidad y se acabó con la posibilidad de establecer una actividad académica seria y sólida (si se exceptúan unas pocas figuras que se resistieron: Carlos Arturo Torres, José María Vargas Vila, Baldomero Sanín Cano y Fernando González). Colombia habría tenido que esperar hasta el final de la República Conservadora para comenzar una actividad filosófica de calidad y sostenida. Así, la filosofía habría surgido por un cambio de actitud que Rubén Sierra Mejía, en una compilación de ensayos filosóficos colombianos del siglo Xx, presenta así:

Aquel cambio de actitud que caracteriza a la ruptura de la práctica filosófica en Colombia, ha permitido tomar a la filosofía de una manera autónoma, con problemas propios y sin una función pragmática inmediata. Se trata ahora de un trabajo profesional y académico que se manifiesta ante todo como actividad eminentemente profesoral, ya que ha sido en la vida universitaria donde ha encontrado su primera motivación nuestra producción filosófica. Es ello la consecuencia de la carencia de fuentes de trabajo intelectual distintas a la que ofrece la cátedra. Ausencia de editoriales, de periodismo cultural y científico, de institutos de investigación, etc. Quizá también debamos ver en esta circunstancia la causa principal del marginamiento del trabajo filosófico colombiano del resto de manifestaciones culturales y de su escasa influencia en la vida nacional (1985, p. 11).

El modo en que Sierra Mejía cuenta esta historia termina por justificar el que hoy en día no haya, o sea muy escasa, la presencia de la filosofía colombiana fuera de las aulas de clase y de los filósofos en el panorama público colombiano, excluyendo de culpa por ello a los filósofos mismos o al tipo de educación que reciben. Al leerse a Sierra Mejía y la historiografía sobre el tema, se entiende bien por qué aquel, en la mencionada compilación de textos filosóficos, no publica 
textos de antes de $1945,{ }^{13}$ y se evidencia además cómo las narraciones históricas promueven la indiferencia hacia los textos de pensadores colombianos antes de la fecha en que ocurre el cambio de actitud que menciona Sierra Mejía.

Más optimistas respecto a la posibilidad de una filosofía en el actual territorio colombiano fueron los miembros del Grupo de Bogotá (en su mayoría, profesores de la Facultad de Filosofía de la Universidad Santo Tomás de Aquino), quienes durante los años ochenta y noventa del siglo $\mathrm{xx}$, y siguiendo los derroteros de la historia de las ideas, usaron la noción de modernidad para vincular el pensamiento colombiano con movimientos intelectuales europeos a partir del siglo XVII (Marquínez Argote, 2001). De nuevo, este tipo de explicaciones dictaminan el proceso local como retrasado, pues solo habrá pensadores modernos en Colombia entrando a la segunda década del siglo Xx. En esta misma línea y con resultados análogos se encuentra el ensayo de Cayetano Betancur (1933) sobre la historia de la filosofía en Colombia, en el cual las transformaciones en la historia de la filosofía de este país se entienden a partir de situaciones específicas originadas en Europa (la Conquista, la Ilustración, la Revolución Francesa...). Este tipo de explicaciones ha hecho carrera y, por ello, es muy común que en las historias de la filosofía locales se vincule el origen de la filosofía moderna con la migración de filósofos españoles hacia América, especialmente en México y Argentina, luego de terminada la guerra civil española en 1939.

Aquí no importa hacer una defensa del pensamiento conservador o afirmar que hubo una filosofía moderna antes de los años veinte o

\footnotetext{
13 No obstante, el profesor Leonardo Tovar ha tenido el cuidado de advertir que: "No debemos asumir simplistamente que solo desde 1946 se conocieron en Colombia los nombres de Cassirer, Husserl, Scheler, Bergson y Heidegger. Una somera revisión de las publicaciones de la época indica que desde mucho antes había personas con interés particular por el filosofar, no en pocas ocasiones con un notable grado de especialización, y quizás con mayor voluntad creativa de la estilada después. Baste mencionar al barranquillero Julio Enrique Blanco (18901985), quien ya desde la segunda década del siglo dio a la luz estudios en torno a filósofos modernos y contemporáneos" (1998, p. 19).
} 
treinta en Colombia. ${ }^{14}$ Aun si se dieran razones sólidas para asumir o rechazar los juicios más habituales sobre el conservadurismo y la filosofía colombiana, resulta evidente que algunas preguntas básicas siguen sin contestarse: ¿qué dicen los textos producidos en Colombia entre 1880 y 1930? ¿Cómo comprenderlos y ubicarlos históricamente más allá de las limitaciones que le ha impuesto la historia de la actividad intelectual atada al quehacer de los gobernantes?

Otros estudios han tomado perspectivas diferentes respecto a la idea de "modernidad", y lo han hecho, justamente, prestando mayor atención a los contenidos específicos de la producción escrita colombiana. Ellos insisten en que pensadores como el tradicionalista Miguel Antonio Caro son precursores del pensamiento moderno en Colombia. Una modernidad parcial, en el caso de Jaime Jaramillo Uribe, quien siguiendo las pautas de una historia de las ideas afirma que este autor (uno de los principales ideólogos y gobernantes de la Regeneración) solo se opuso parcialmente a la modernidad. ${ }^{15}$ Por su parte, Óscar Saldarriaga Vélez, a través de lo que él mismo llama una bistoria epistemológica (Domínguez Miranda, 2008, p. 9), muestra que autores como Caro concretaron, para Colombia, una modernidad católica (Saldarriaga Vélez, 2004, pp. 41-59; Domínguez Miranda, 2008, pp. 1-31). Entre tanto, Santiago Castro-Gómez (2005), bajo las pretensiones teóricas de los estudios poscoloniales, ha mostrado que el pensamiento moderno llegó al actual territorio colombiano desde el siglo XVIII con la ilustración criolla y, en lugar de ser útil para alcanzar la libertad, el progreso técnico o el ingreso al circuito de la economía

\footnotetext{
14 A partir de los años sesenta en Colombia hubo un debate sobre el comienzo de la filosofía en Colombia. Las partes en conflicto afirmaron, por un lado, que hubo desde la Colonia; por otro, liderados por Rubén Jaramillo Vélez y Rubén Sierra Mejía, afirmaban que solo hubo filosofía a mediados de la década de los cuarenta (López, 2012, pp. 309-327).

15 Cuando presenta la forma en que se introdujeron modificaciones que ponían a Colombia a tono con otras naciones del mundo, afirma que hubo "[un] intento de reemplazar la concepción nobiliaria de la vida, por la burguesa, de sustituir el caballero cristiano por el Homo economicus, [este intento] puede iluminarnos otros dos hechos de la historia espiritual de Colombia en el siglo pasado: el anhelo de asimilar la ciencia moderna y el entusiasmo con que recibieron corrientes de ideas como el racionalismo y el positivismo casi todos los hombres educados de Colombia en el siglo XIX, si exceptuamos, parcialmente, la figura de Miguel Antonio Caro" (Jaramillo Uribe, 2001, p. 20).
} 
mundial, sirvió para perpetuar la dominación colonial desde los tiempos de los Borbones e, incluso, luego de las guerras de Independencia y a lo largo del siglo XIX.

Las investigaciones de Saldarriaga y Castro-Gómez evitan postular a "la modernidad" como un destino necesario de los hechos, los hombres y las obras que tuvieron lugar en el actual territorio colombiano. ${ }^{16}$ Castro-Gómez señala, más bien, que la modernidad es una herencia colonial que determina la condición periférica que este país ocupa en el todo de un "sistema mundo"; mientras que Saldarriaga, siguiendo los trabajos de Michel Foucault, muestra que Colombia procesó, de la mano de la Iglesia católica y el pensamiento conservador, la modernidad europea y, al menos en términos epistemológicos, habría encontrado, además de un camino para dar cuenta de la formación del sujeto moderno en Colombia, respuestas a los retos que la Ilustración planteó al conocimiento en general y a su relación con instituciones como la Iglesia católica (Saldarriaga Vélez, 2004, pp. 41-59).

Si bien estas breves líneas no hacen justicia a los detalles de muchos de los estudios referidos y no referidos aquí que directa o indirectamente se ocupan de la actividad intelectual en Colombia, sí permiten indicar cómo buena parte de dichos estudios se vinculan con reflexiones en torno a una noción que se define de muy variadas maneras. Por lo regular, la palabra modernidad, además de indicar un complejo de procesos técnicos, políticos y culturales, se la usa como una teleología a la cual debería llegarse (secularización, capitalismo, incorporación al mercado mundial o normalidad). O se la usa para homogeneizar la producción

16 En un texto sobre la historia de la educación primaria en Colombia y la formación de la "infancia" como una cuestión de interés para la administración pública, la Iglesia y los intelectuales, Saldarriaga, Sáenz y Ospina afirman: "Este trabajo ha tratado sobre la escuela y el saber pedagógico, que por autodefinición han sido un dispositivo de modernización para las sociedades occidentales desde fines del siglo XVII. Pero no hemos querido aceptar este término - modernización - ni como un proceso evidente por sí mismo, ni tampoco como un modelo unívoco al cual nuestra realidad se ajustaría o no. De hecho [...] lo hemos usado en tres sentidos: uno histórico, para entender cómo lo emplearon los actores de nuestro periodo de estudio; uno estratégico, para describir un conjunto de discursos y dispositivos aplicados a la sociedad, y un tercer sentido metodológico, para analizar el saber pedagógico y la escuela como una práctica de saber y de poder" (1997, p. 469). 
intelectual colombiana: sea por la resistencia que algunos escritores apoyados por el gobierno y bajo los principios del pensamiento hispanista o el catolicismo hicieron ante aspectos concretos del cambio científico, social y político; sea por la sumisión o por la obsesión de hacerlos encajar en la historia del pensamiento europeo, debido a la importancia que se le da a Europa como centro productor de conocimiento o como causa eficiente del cambio; sea por la igualación de las fuentes desde una teoría del poder que estandariza los productos intelectuales desde la Colonia hasta las primeras décadas del siglo XX a través de una modernidad/colonialidad; ${ }^{17}$ sea, finalmente, por las formas de conocimiento que se alojan en un orden epistemológico importado desde Europa y que estructuraría las diversas posiciones intelectuales y políticas de un periodo, incluso aquellas antagónicas. ${ }^{18}$

Para evitar que esta noción se convierta en un obstáculo analítico, en una sombra que oculta el contenido concreto de los textos producidos en Colombia, propongo no abandonarla, sino ponerla en suspenso

17 Esto puede apreciarse en los dos últimos libros de Castro-Gómez. En la introducción de Tejidos oníricos, cuando Castro-Gómez presenta a este libro y al anterior como parte de un proyecto en el que se hace una historia cultural del capitalismo en Colombia, dice: "Inicialmente había pensado concentrarme en el proyecto gubernamental de liberalismo radical (18631886), pero al empezar a construir el archivo me di cuenta de que, con algunas variaciones, este proyecto me llevaría a conseguir resultados similares a los ya presentados en La bybris del punto cero. La composición social del país no había cambiado mucho respecto a lo ya estudiado en el siglo XVIII, y aunque sí es posible rastrear la emergencia de nuevas tecnologías de gobierno, no podía hablarse, sin embargo, de procesos de industrialización en esa época, que era justo lo que estaba esperando encontrar" (Castro-Gómez, 2005, pp. 11 y 12).

18 Los trabajos de Saldarriaga son un claro ejemplo de ello, pues la forma en que da cuenta del pensamiento colombiano sigue siendo dependiente de la estructura completa de un libro de Michel Foucault sobre la formación de dos sustratos epistemológicos en Europa (entre los siglos XVII y XVIII uno y más o menos durante todo el siglo XIX el otro): "Si creemos a la investigación de Les mots et les choses, el cambio epistémico en Europa arrastró de modo prácticamente simultáneo a las ciencias de la vida, el trabajo y el lenguaje. Y si la 'Cuestión Textos' fue la manifestación local de la crisis de la configuración racional, podría adelantarse una cauta hipótesis para Colombia, y es que esta mutación epistémica se dio en Colombia, visiblemente, sobre la vía del Lenguaje, por el salto de la Gramática General a la Filología, proceso en el cual se también se incorporaron algunos discursos de la Fisiología y la medicina experimental, ante todo como discursos estratégicos con fines políticos e ideológicos" (Domínguez, 2008, p. 40). 
como categoría de análisis y, más bien, convertirla en objeto de investigación. Ello, al menos, desde dos puntos de vista. El primero evaluando el uso que hicieron del término modernidad quienes ejercieron la actividad intelectual durante de la Regeneración y la República Conservadora (pues usaron el término). El segundo, comparando ese uso con el que los investigadores en el presente hacen de este. La importancia de revisar estos usos responde a que con esta noción nuestros contemporáneos, como se mencionó atrás, asignan valores al pasado (atraso, lentitud, postergación, simulación y anormalidad) y homogeneízan las fuentes, pero además, en no pocas ocasiones, usan el término en sentidos análogos a los que se encuentran en las fuentes mismas, dejando ver cómo, en cierto sentido, aún comulgan con las esperanzas y deseos de aquellos a quienes estudian.

Esta propuesta de trabajo en torno al doble uso de la noción modernidad no puede perder de vista que los diversos procesos que se nombran con esta palabra son también resultado de la colonización y los diferentes juegos de intereses locales que se gestaron antes de la Independencia y después de este. ${ }^{19}$ Tales juegos de intereses, además de implicar efectos valorativos sobre la documentación colombiana tan claros y problemáticos como los del término que se propone poner en suspenso (modernidad), generan un problema metodológico: la toma de partido, consciente o no, por alguna de las facciones en pugna durante los procesos que se estudian (así el historiador se convierte en juez y parte del proceso que trata de enfocar). ${ }^{20}$

19 Al respecto afirma Jorge Orlando Melo: "El hecho de que la independencia se hubiera logrado en un momento en el que Inglaterra aparecía como el modelo por excelencia del desarrollo, y los Estados Unidos como el más exitoso ejemplo del proceso de crecimiento de un pueblo recién liberado, hizo que desde entonces se identificara con el logro de los objetivos de independencia nacional el establecimiento de una economía capitalista y de un sistema político liberal y basado en la soberanía popular. Como esta opinión fue común a todos los sectores de la élite y a los dirigentes de los dos partidos que se configuraron a mediados del siglo pasado, los objetivos del proyecto modernizador no se vieron alterados substancialmente por las vicisitudes de las luchas políticas del siglo XIX ni por la inestabilidad del periodo. Para 1850 este proyecto modernizador hacía parte del ideario fundamental de los grupos dirigentes del país" (Viviescas y Giraldo, 1991, p. 231).

20 "Juez" porque se pone en la disyuntiva de valorar los procesos como moderno o no; "parte" por la necesaria toma de partido que esta valoración exige. Seguramente, Jorge Orlando 
Por esta vía se promueve, además, una comprensión histórica de quienes se identifican y fueron identificados con el título de "escritores" como superhéroes o supervillanos, como meros funcionarios de la modernización que la habrían potenciado o retrasado. Se perpetúa la lectura del trabajo intelectual de estos personajes como simple imitación de los centros productores de saber o como mera herramienta de los gobernantes de turno. En el mejor de los casos, se muestran sus obras como si fueran el trabajo de mentes brillantes e incomprendidas por quienes los rodeaban, pues no existía ni un medio que les permitiera surgir, ni una comunidad de "pares".

En síntesis, se olvida que los textos, además de condiciones del entorno fundamentales para su comprensión (situaciones específicas que los motivan, luchas de intereses, promoción y emulación de modelos foráneos), dependen también de procesos de elaboración textual que son determinantes (métodos de investigación locales o importados, inquietudes, respuestas, soluciones, temas de pasajeros o que constituyen una tradición). Por ello, para comprender esos textos que tanto se han usado y se usan en explicaciones historiográficas sobre el pasado colombiano, hace falta mostrar sus contenidos concretos. Es decir, se requiere dar cuenta del ejercicio efectivo de la escritura y, además, aclarar cómo pensar las relaciones de esos productos intelectuales (su condición lingüística) y su incuestionable conexión con los gobiernos

Melo se refiere a esta toma de partido en el último párrafo de un artículo sobre la modernidad y la modernización en Colombia, cuando afirma: "El texto anterior constituye ante todo un registro de un proceso que se ha impuesto con una fuerza que, retrospectivamente, tiene cierto aire engañoso y ominoso de ineluctabilidad. Quizás en sus inflexiones irónicas haya alcanzado a sugerir que la modernidad no es un beneficio inequívoco y que los costos de su triunfo han sido tal vez excesivos. Así como para los indígenas del siglo XVI carecía de interés una evangelización y una civilización que se impuso mediante la muerte del $90 \%$ de quienes debían beneficiarse de ellas, debe preguntares cuál es la significación del proceso de modernización para las comunidades indígenas cuya cultura se ha destruido, para las víctimas de 40 años de violencia, o para las personas que han vivido en la miseria desde que ésta fue generada por el progreso económico. Y la misma trama de la exposición debería permitir preguntarse si no es prematuro el abandono de todas las alternativas al capitalismo que conocemos y si será posible reconstruir el delgado tejido de nuestra civilización sin proponer nuevas utopías de convivencia social y de ordenamiento económico en un país que se resigna cada vez más al caos y a la violencia, con la casi única condición de que continúe el desarrollo económico" (Viviescas y Giraldo, 1991, p. 245). 
de turno; asimismo, establecer las diversas formas de interacción social de quienes escribían con sus pares nacionales y extranjeros, además, claro está, de otros sectores de la sociedad que los seguían en la plaza pública, los conocían a través de sus publicaciones, los respaldaban o rechazaban debido a las filiaciones partidistas o a juegos de intereses específicos (económicos, laborales o familiares).

\section{El mínimo textual en el terreno común donde ocurren los antagonismos}

El acercamiento a la producción escrita en el actual territorio colombiano no puede estar limitado al uso que recibió por parte de los administradores de lo público, ni al seguimiento o desviación de modelos regidos por una idea de la "modernidad" y las palabras asociadas a ella; tampoco puede reducirse a su utilidad inmediata en debates ideológicos o en la resolución de problemas públicos concretos. Estos factores son importantes, pero la historicidad de la escritura, esa actividad concreta que define a un grupo social específico, también debe ser pensada desde el ejercicio mismo de escribir. Esto, claro está, si se tiene como objetivo entender los textos escritos producidos en un periodo, sea para dar cuenta de su propia naturaleza y la forma en que en ellos se concreta un tipo de actividad, sea para vincular dicha actividad con otras (gobernar, generar opinión pública y transmitir conocimiento), sea para usar dichos textos como fuente para explicaciones de otro orden (como de hecho ocurre en bastantes trabajos de historia y de otras disciplinas sociales).

En síntesis, una investigación sobre la revisión de la naturaleza textual de la producción escrita servirá para precisar cómo en dicha producción aparece la idea de modernidad. Así, no solo se consigue un principio de lectura y organización de los documentos que surge desde un concepto que aparece y se define en ellos mismos, sino una primera limitación razonable de las fuentes. Además, la observación de este concepto en cuanto objeto de investigación, desbloquea algunos de los inconvenientes de lectura que han suscitado las investigaciones recientes que usan a dichas fuentes en sus trabajos; y, más importante aún, permite trazar un puente directo de comparación entre estas últimas 
y las investigaciones recientes. En consecuencia, y dada la particular insistencia en el papel desempeñado por los gobiernos conservadores colombianos en la inserción de este país en la modernidad, valdría la pena identificar los diversos usos de la noción modernidad entre 1880 y 1930 en los textos considerados por sus autores y sus contemporáneos como ciencias sociales y filosofía, contrastando tales usos con los usos de la misma noción en el presente.

Es cierto que la actividad intelectual, y concretamente la escritura, está determinada por juegos de intereses, formas ideológicas, relaciones con los copartidarios y administración pública; pero responde también a exigencias definidas por la producción textual misma, tal como la llevaban a cabo quienes se identifican con dicha actividad. En su momento, dichas exigencias debieron de servir para tratar como pares a copartidarios y oponentes, específicamente para señalar como "dignos" de ser leídos, apoyados o refutados los textos que producían a través de nuevas publicaciones escritas. Es de esperar — en el caso de que tal supuesto operativo fuera correcto- que las mencionadas exigencias constituyan un terreno común a las diferentes tendencias políticas y religiosas que públicamente debatían.

La posibilidad de identificar este terreno común de la actividad intelectual ha sido indicada por otros autores: además de los trabajos de Saldarriaga ya mencionados, se cuenta con el estudio sobre el debate de la degeneración de la raza en Colombia de Carlos Noguera, quien a propósito el debate en general dice:

Más allá de las polémicas estrictamente darwinistas y en el marco de las preocupaciones generadas en torno a la idea de la regeneración racial del pueblo colombiano, a finales del siglo XIX y durante las primeras décadas del siglo $\mathrm{xx}$, los nuevos saberes médicos e higiénicos fueron consolidando una especie de "moral biológica" que se oponía a la moral católica, y a partir de la cual los intelectuales considerados "modernos" pretendieron arrebatar a la Iglesia, y a los intelectuales tradicionales, el control y gobierno de la población. Esta nueva "moral biológica", fundamentada en saberes como la antropología, la criminología, la psicología experimental, 
la higiene, y la medicina, concebía la acción del individuo como un resultado de factores, entre ellos, la herencia y el medio geográfico, restando importancia a la voluntad como suprema guía de la acción humana de acuerdo con la doctrina cristiana. A ella se sumaron intelectuales de ambos partidos políticos, y aún religiosos, hecho que señala, antes que un problema ideológico un acontecimiento discursivo, es decir, la hegemonía que un discurso y unas prácticas logran en las posiciones que asumen los individuos en un momento histórico determinado (Noguera, 2003, p. 210).

En su libro, Noguera afirma que la sociedad colombiana comenzó un proceso de transformación en el orden moral a finales de la primera década del siglo xx y comienzos de la de los veinte. Tal proceso iba más allá de los debates ideológicos entre los diversos partidos políticos y superaba también las oposiciones religiosas. Allí, el autor apela a un orden discursivo (que, salvo por la frase citada, no especifica a lo largo de su trabajo) en el que unos discursos y unas prácticas tienen primacía respecto de otras. Así, él define a la necesidad de establecer una moral secular como el terreno común en el que las clásicas fuerzas antagónicas de la historia de Colombia se encuentran.

Otros trabajos de, por ejemplo, Álvaro Medina sobre el comienzo del arte contemporáneo en Colombia; ${ }^{21}$ Martha Herrera, a propósito del papel de la escuela en la modernización de este país, ${ }^{22}$ o Cristina Rojas,

21 "La ideología de los grupos, que también se refleja, aunque de un modo más complejo, en sus posiciones ante el arte, tampoco se distinguen en sus enunciados en el caso de la Exposición del 99. Porque si Garay era un academicista, Acevedo Bernal no lo era menos. Desde el punto de vista estético, no había alternativa en los dos artistas escogidos como banderas de choque por las partes en conflicto. El esplendor del academicismo, iniciado por Garay, se iba a cerrar con Acevedo Bernal para prolongar sus influencias en este siglo. La identificación de las clases dirigentes y de la élite culta de la Colombia de entonces, era monolítica en su entusiasmo por la Academia como concepción estética. Tanto el regenerador Rafael Núñez como los jóvenes intelectuales Max Grillo y Rubén J. Mosquera o con el pintor y dirigente liberal Pedro Carlos Manrique, coincidían todos en su culto a la Academia" (Medina, 1978, p. 45).

22 Quien, apropósito de la apropiación que los intelectuales colombianos de ambos partidos hicieron de la Escuela Nueva, afirma: "En síntesis, las élites y los intelectuales que compartían su visión del mundo, concebían las transformaciones de la sociedad desde la óptica de la consolidación del Estado nación, al tiempo que sus representaciones sobre la población 
sobre los imaginarios de las élites colombianas en torno a la nación, ${ }^{23}$ han señalado la insuficiencia del partidismo para interpretar la producción intelectual de las élites colombianas; no importa si quienes la redactaron se dedicaron también a las artes plásticas, a la educación o a la administración pública. ${ }^{24}$

A estos y otros trabajos se une el libro Pilar Melgarejo, titulado El lenguaje político de la Regeneración (2010). Allí se traza un lenguaje común entre el porfiriato mexicano (1876-1911) y la Regeneración colombiana, no obstante las diferencias ideológicas entre ambas formas de gobierno. También se unen algunas investigaciones recientes sobre el

colombiana les llevaba a considerarla como un conglomerado incapaz de llevar a cabo acciones autónomas y a favor de sus intereses. De esta manera, las masas debían ser dirigidas por las élites, concibiéndose la reorganización institucional de la sociedad y de las condiciones de los sectores populares, como una estrategia organizada desde arriba, aunque para ello se hiciera uso de la movilización popular para lograr el consenso político" (Herrera, 1999, p. 112).

23 Quien busca establecer una historia de la nación más allá del partidismo, a través del concepto deseo civilizador, entendido como "lugar de encuentro entre el pasado colonial y el futuro imaginado, como paso entre barbarie y civilización, fue violento. La violencia de la representación estaba asentada en actos de supresión de la historia: las historias nativas, locales y femeninas no tuvieron lugar en el proceso civilizador. La violencia también estaba asentada en el establecimiento de jerarquías diferenciadoras y en estrategias de civilización impresas en los cuerpos de los criollos, los mulatos, los zambos, los negros y los indios, fueran estos hombres o mujeres" (Rojas, 2001, p. 72).

24 Renán Silva, por su parte, ha insistido en mantener esta diferencia en su estudio sobre la República Liberal: "Lo que parece ser distintivo de los intelectuales liberales en este punto es, en primer lugar el haber acentuado los 'factores sociales' de las configuraciones culturales y el haber construido una cierta 'antropología positiva' del 'pueblo colombiano', 'pueblo' que en enfoque más conservadores y tradicionalistas era visto precisamente como la 'causa' del atraso del país y de su propio fracaso histórico, tal como aparecía ante sus ojos [...] En segundo lugar fue rasgo distintivo de la invención liberal de la cultura popular, el haberla pensado sobre la base de una matriz folclórica, es decir, de un acercamiento a lo 'popular' que lo considera al tiempo como típico y como exótico, y sobre todo como encarnación del 'alma nacional' y depositario de tradiciones intemporales que son la base de todo futuro posible" (2006, p. 225). No obstante, en una nota al pie de la misma página afirma: "Desde luego que intelectuales liberales también produjeron análisis seudoantropológicos — ¿O preantropológicos? - del "pueblo colombiano", de los cuales se podrían extraer visiones negativas de lo "popular" (p. 225). La nota continúa mostrando los ejemplos de Armando Solano, Francisco Socarrás y Luis López de Mesa, y así termina. Como se ve, la diferenciación partidista usada debe ser inmediatamente matizada para poder seguir el relato, procedimiento innecesario si se prescinde de dicha diferenciación. 
trabajo intelectual de Miguel Antonio Caro (López, 2008a, pp. 1-40, y 2008b, pp. 77-94), que mostraron nuevas líneas de interpretación de su obra y evitaron encuadrarla dentro de los márgenes del partidismo y la religión. En síntesis, una investigación sobre el uso de la noción de modernidad en las ciencias sociales y la filosofía sigue el camino trazado durante casi dos décadas por los trabajos mencionados a través de la identificación de las exigencias que dieron forma a la producción escrita en Colombia.

Tal vez, debido a las estrechas relaciones entre la vida pública como escritor y como parte del gobierno, el terreno que definen dichas exigencias no cuente con la creciente autonomía que algunos autores identifican como propia de los escritores y en general artistas europeos a partir del Renacimiento; ${ }^{25}$ falta de autonomía que, como se mencionó, el mismo Sierra Mejía considera necesaria para la consolidación de una filosofía "normal" en Colombia. No obstante, parece razonable suponer que quienes se encargaban de hacer las publicaciones tenían algún criterio de selección, y por más intereses que estuvieran en juego, había mínimos que debían cumplirse, referencias, calidad gramatical, estructura lógica, etc. Además, seguramente no todos los ataques y críticas publicadas se contestaban, no todos los textos se reseñaban, se citaban y se leían. Es muy probable también que la comunidad misma de escritores considerara que incluso algunas publicaciones no merecían el esfuerzo de ser refutadas o recomendadas. Es decir, aun con todos los condicionamientos que daban forma a la producción escrita, tuvo que existir un "mínimo textual" en el que lo escrito debía bastarse a sí mismo y alcanzar algún valor para quienes ejercían la actividad intelectual en el momento. Claro está, no se puede por ello perder de vista que el mínimo habría sido una condición necesaria y no suficiente para la publicación y el reconocimiento de la comunidad a la que pretendía pertenecer. Además, aunque en Colombia este

\footnotetext{
25 Autonomía que tiene que ver con el grado de independencia que se mueven en un campo de poder concreto: "A medida que el campo intelectual y artístico adquiere autonomía y se eleva simultáneamente el status social de los productores de bienes simbólicos, los intelectuales tienden progresivamente a entrar en el juego de los conflictos entre fracciones de la clase dominante por cuenta propia y no ya solamente por poder o por delegación" (Bourdieu, 2002, p. 106).
} 
tipo de escritura no se profesionalizaría hasta después de 1930 y la posibilidad de ser "masivo" no llega hasta la aparición de la Escuela Normal Superior (1937-1944) y la fundación del Instituto de Filosofía de la Facultad de Derecho de la Universidad Nacional de Colombia (1945), es muy fácil encontrar documentos producidos en el actual territorio colombiano que, al menos desde comienzos del siglo XIX desde mucho antes incluso- ya eran reconocidos por sus autores y sus contemporáneos como textos de historia o de filosofía, algo más adelante, de disciplinas como sociología y antropología. ${ }^{26}$

El mínimo textual establecerá la serie de condiciones textuales — relativas a la práctica concreta de la escritura - que hacen de un documento un producto con el suficiente valor para ser objeto de publicación, discusión y tema de escritura entre quienes tenían por oficio ser escritor (quienes eran reconocidos por sus pares y publicaban documentos con algún impacto entre la comunidad de la cual hacían parte). Este mínimo textual no puede establecerse a priori; su historicidad, válgase esta verdad de Perogrullo, implica que solo desde las fuentes mismas sea visible su talante.

Este no es el lugar para explorar a fondo las ventajas y límites del concepto minimo textual. Por ello baste con decir por ahora que el establecimiento del mínimo textual revela aspectos fundamentales del espacio común que miembros de la Iglesia y seculares, liberales y conservadores, defensores del gobierno y opositores, gentes de izquierda y derecha, entre otros, compartían para llevar a cabo un oficio que, además de curas, políticos, élites, burgueses, obreros, amas de casa,

\footnotetext{
26 La extensa obra de José Manuel Restrepo reconocida como historia por él y sus contemporáneos comienza a publicarse desde 1809 hasta mediados del siglo XIX (con reediciones posteriores a lo largo del siglo xx). Por citar un solo ejemplo de textos filosóficos, véase el polémico libro Estudio sobre el utilitarismo, de 1869 (1962), una ácida crítica que el entonces joven Miguel Antonio Caro elabora para refutar las tesis de Jeremías Bentham y a su más férreo promotor y defensor, Ezequiel Rojas, quien venía publicando textos utilitaristas desde, al menos, 1848. De otras disciplinas sociales puede contarse el conocido discurso que en 1882 dio Salvador Camacho Roldán, titulado "El estudio de la sociología" (González, 1997, pp. 69-103), además del variopinto "Las tribus indígenas del Magdalena”, de Jorge Isaacs, de 1884 (1983).
} 
etc., les permitía llamarse a sí mismos y ser llamados por otros escritores. Tal espacio, como ya se mostró, algunas investigaciones han empezado a perfilar desde el estudio de otras prácticas intelectuales como la medicina, la educación, las artes plásticas y el gobierno.

Solo resta decir que, como resulta evidente, las fuentes para llevar a cabo un trabajo así deben regirse por la práctica específica que interesa: la escritura. Esta ha sido reconocida también como la característica central de lo que hasta aquí se ha evitado designar — si se exceptúan las citas textuales - con el sustantivo intelectual y, acorde con la naturaleza de la práctica que interesa, se ha preferido llamar escritor. También se han evitado nombres como letrados, según la usanza de Ángel Rama, o la de publicistas, como prefiere llamarlos Frédéric Martínez, porque muchas de estas palabras cumplen papeles similares a la ubicación partidista, la idea de modernidad o la filiación a las administraciones de turno, es decir, establecen criterios de lectura de las fuentes que ocultan su carácter textual. ¿Hará falta una definición del escritor? ¿Aclarar la naturaleza de sus actividades y mostrar sus efectos en otro tipo de actividades no será suficiente para entenderlo? Sin pretender ser exhaustivo en la respuesta, diría que es tiempo de comenzar una investigación que revise la práctica de la escritura para, desde ella, comprender el actor que la ejecuta; así podríamos liberarnos de las preconcepciones que suponen las definiciones previas de los agentes y que ocultan la especificidad de sus actos.

\section{Referencias}

Arias Trujillo, R. (2007). "Los Leopardos”: una historia intelectual de los años 1920. (1 a ed.). Bogotá: Universidad de los Andes, Facultad de Ciencias Sociales, Departamento de Historia.

Betancur, C. (1933). La filosofía en Colombia. Anales de la Universidad de Antioquia, vi (2), 15-77.

Bourdieu, P. (2002). Campo de poder, campo intelectual: itinerario de un concepto. Buenos Aires: Montressor.

Caro, M. A. (1962). Estudio sobre el utilitarismo. En C. Valderrama Andrade (Ed.), Obras I: M. A. Caro (pp. 7-271). Bogotá: Instituto Caro y Cuervo. 
Castro-Gómez, S. (2005). La bybris del punto cero: ciencia, raza e ilustración en la Nueva Granada (1750-1816). Bogotá: Editorial Pontificia Universidad Javeriana.

Domínguez Miranda, M. (2008). Algunas facetas del pensamiento de Miguel Antonio Caro. Bogotá: Editorial Pontificia Universidad Javeriana.

Gil Olivera, N. A. y Ortiz Rivas, H. A. (2008). Pioneros de la filosofía moderna en Colombia (siglo XX). Bogotá: Ibáñez.

González R., J. E. (1997). Positivismo y tradicionalismo en Colombia. Bogotá: El Búho.

Henderson, J. (2006). La modernización en Colombia: los años de Laureano Gómez. 1889-1965. Medellín: Universidad de Antioquia.

Herrera C., M. C. (1999). Modernización y Escuela Nueva en Colombia (1a ed.). Bogotá: Universidad Pedagógica Nacional.

Isaacs, J. (1983). Las tribus indígenas del Magdalena. Bogotá: Incunables.

Jaramillo Vélez, R. (1998). Colombia: la modernidad postergada. Bogotá: Temis. Jaramillo Uribe, J. (2001). El pensamiento colombiano en el siglo XIX. Bogotá: Alfaomega.

Kalmanovitz, S. (2001). Las instituciones colombianas en el siglo XX. Bogotá: Alfaomega.

López J., C. A. (2008a). Lenguaje y autoridad: totalidades localizadas. En M. Domínguez Miranda (Ed.), Algunas facetas delpensamiento de Miguel Antonio Caro (pp. 1-40). Bogotá: Editorial Pontificia Universidad Javeriana.

López J., C. A. (2008b). La politización en las lecturas canónicas: Miguel Antonio Caro Lector de Jorge Isaacs. Memoria y Sociedad, 12 (25), 77-94. López J., C. A. (2012). Normalización de la filosofía y filosofía latinoamericana en Colombia: vivencia de un proceso. Universitas Philosophica, 58 (29), 309-327.

Marquínez Argote, G. (2001). La filosofía en Colombia: historia de las ideas. Bogotá: El Búho.

Medina, Á. (1978). Procesos del arte en Colombia (vol. 34). Bogotá: Andes.

Melgarejo, P. (2010). El lenguaje politico de la regeneración en Colombia y México. Bogotá: Editorial Pontificia Universidad Javeriana.

Noguera, C. (2003). Medicina y política: discurso médico y prácticas higiénicas durante la primera mitad del siglo XX en Colombia. Medellín: Universidad Eafit.

Nieto Arteta, L. E. (1958). El café en la sociedad colombiana. Bogotá: La Soga al Cuello. 
Pérez Benavides, A. C. y Hering Torres, M. S. (2012). Historia cultural desde Colombia: categorías y debates. Bogotá: Pontificia Universidad JaverianaUniversidad de los Andes-Universidad Nacional de Colombia.

Rodríguez Valbuena, M. G. (2003). La filosofía en Colombia: modernidad y conficto. Rosario: Laborde.

Rojas, C. (2001). Civilización y violencia: la búsqueda de la identidad de la Colombia del siglo XIX. Bogotá: Norma.

Romero, F. (1944). Sobre la filosofía en Iberoamérica. Buenos Aires: Lozada.

Saldarriaga Vélez, Ó. de J. (2004). Gramática, epistemología y pedagogía en el siglo XIX: la polémica colombiana sobre los elementos de ideología de Destutt de Tracy (1870). Memoria y Sociedad, 8 (17), 41-59.

Saldarriaga Vélez, Ó. de J., Sáenz Obregón, J. y Ospina, A. (1997). Mirar la infancia: pedagogía, moral y modernidad en Colombia, 1903-1946. Medellín: Colciencias-Foro Nacional por Colombia-Ediciones Uniandes-Editorial Universidad de Antioquia.

Sánchez Gómez, G., Pécaut, D. y Uricoechea, F. (2003). Los intelectuales y la política. Bogotá: IEPRI-FICA.

Sánchez, G. (1998). Intelectuales... poder... y cultura nacional. Análisis Político (34), 115-138.

Sierra Mejía, R. (1985). La filosofía en Colombia. Bogotá: Procultura.

Silva, R. (2006). Sociedades campesinas, transición social y cambio cultural en Colombia: la encuesta folclórica nacional de 1942: aproximaciones analíticas y empiricas. Medellín: La Carreta.

Tovar, L. (1998). La normalización filosófica en Colombia. Cuadernos de Filosofía Latinoamericana (72-73), 19-25.

Uribe Celis, C. H. (1985). Los años veinte en Colombia: ideologia y cultura. Bogotá: Aurora.

Uribe Escobar, J. D. (2006). Evolución de la educación en Colombia durante el siglo XX. Recuperado de http:/ / www.banrep.gov.co/documentos/publicaciones/revista_bco_notas/2006/febrero.pdf.

Urrego Ardila, M. A. (2002). Intelectuales, Estado y nación en Colombia: de la Guerra de los Mil Días a la Constitución de 1991. Bogotá: Universidad Central-Siglo del Hombre.

Viviescas, F. y Giraldo Isaza, F. (Eds.), (1991). Colombia: el despertar de la modernidad. Bogotá: Foro Nacional por Colombia. 
